\title{
Evaluation of Outcome of Care in Patients with Haemophilia
}

Karen Beeton

Principal Lecturer Department of Physiotherapy, University of Hertfordshire

Honorary Lecturer, Royal Free and University College Medical School, London

Address for correspondence

Department of Physiotherapy

University of Hertfordshire

College Lane

Hatfield AL10 9AB UK

01707284114 (tel)

01707284977 (fax)

email: K.S.Beeton@herts.ac.uk

\section{Key words}

Haemophilia, outcome, quality of life, physical assessment, orthopaedic assessment 


\section{Abstract}

Haemophilia is a potentially disabling condition associated with high financial costs and so the need for robust measures to evaluate outcome of care is essential. This paper is a review of some of the outcome measures commonly used to evaluate treatment in haemophilia and includes quality of life measures, evaluation of the musculoskeletal system and orthopaedic surgical procedures. Quality of life questionnaires are discussed with particular reference to the SF36 and AIMS2. Results of published studies to date demonstrate variable results. Overall having haemophilia appears to reduce quality of life compared to normal population figures. Several factors are perceived to reduce quality of life and these include being HIV positive, having impairments and a history of orthopaedic surgery. The evaluation of the musculoskeletal system is important in order to detect any deterioration over time. Various standardised measurement tools are outlined. Orthopaedic surgical procedures have also been evaluated in patients with haemophilia. To date the Hospital for Special Surgery Knee rating scale has been most commonly used to evaluate the outcome of total knee replacement. The limitations of this system for patients with haemophilia are outlined. Overall these measures provide useful tools to evaluate outcome but none have been developed specifically for patients with haemophilia. Further studies would be useful to evaluate these tools and others in more depth. 
Assessing the outcome of treatment is an essential component of evaluation of practice. Haemophilia is a potentially disabling condition associated with very high financial costs and so the need for the evaluation of interventions is especially important. This paper will review commonly used measures in the evaluation of outcome in haemophilia. These include health related quality of life (QoL) questionnaires and outcome measures to evaluate impairments and orthopaedic surgical procedures commonly used for haemophilic patients. Finally, some recommendations for future research will be discussed.

Musculoskeletal dysfunction is a common manifestation of haemophilia particularly in the severely affected patient. Repeated bleeding into joints, commonly knees, elbows and ankles can lead to arthropathy with associated pain, loss of range of movement and loss of function [1]. Medical management focuses on prompt and adequate treatment with factor replacement to minimise the effects of bleeding and prophylactic regimens are recommended for severely affected patients [2] [3] [4]. Over the last twenty years the usage of factor replacement has risen exponentially predominately as a result of the increased use of prophylaxis [5]. Factor replacement is a very expensive commodity. In 1994 the cost of factor replacement alone in the United Kingdom was in the region of $£ 50$ million [6] accounting for 50$85 \%$ of the total expenditure of haemophilia care [5]. Purchasers need to be satisfied that these high cost resources are beneficial in improving health. Despite the availability of factor replacement, patients still present with musculoskeletal bleeds and their sequelae and older patients who did not have the benefit of adequate factor replacement in their childhood may develop joint arthropathy. This requires monitoring over time and specific treatment, including physiotherapy or surgery, may be required if conservative treatment fails.

Recent Government reports have highlighted the need to use robust measures to assess the outcome of care for all patients [7]. The Haemophilia Chartered Physiotherapists Association (HCPA) Standards for Haemophilia [8] identified that each physiotherapy session should be evaluated using appropriate assessment tools. In the recently revised Chartered Society of Physiotherapy Core Standards of Physiotherapy Practice [9], standard 6 states 'Taking account of the patient's problems, a published, standardised, valid, reliable, and responsive outcome measure is used to evaluate the change in the patient's health status'. There are a number of instruments that can be used to evaluate outcome including impairment measures, pain scales, functional scales, activity levels and QoL measures. In view 
of the considerable costs associated with haemophilia management, the need to evaluate the impact of various factor replacement regimens [10], [11] and any changes in health status following physiotherapy and other interventions is paramount.

\section{Evaluation of Quality of Life (QoL)}

Health related QoL is a broad term that covers a number of different concepts including physical status, role, social integration, psychological status and perceptions of health [12]. Quality of life instruments need to include these different domains in their questionnaires. There is debate in the literature regarding whether the measurement of each domain or an overall score is more important in evaluating different interventions [13], [14]. According to Fuhrer [15] many studies carried out on people with physical disabilities in the United States of America (U.S.A.) have reported lower levels of QoL compared to the normal population. Other authors however, have identified that a good QoL is often reported in patients with marked disabilities [16], [17]. This suggests that QoL is a complex phenomena and the need for multiple methods of evaluation are required.

Standardised questionnaires have been used to evaluate QoL in patients with haemophilia. The Medical Outcomes Study Short Form 36 (SF36) is a generic measure of QoL that is self-administered. It consists of eight domains, physical functioning, role limitations due to physical problems and role limitations due to mental problems, bodily pain, social function, mental health, vitality and general health perceptions providing an overall score for physical and mental domains [18]. The Arthritis Impact Measurement Scale 2 (AIMS2) is a revised and expanded version of the original AIMS self administered questionnaire designed to assess health status in patients with arthritic conditions. It includes physical, social and emotional dimensions in twelve categories and also includes sections on the impact of arthritis, levels of satisfaction, areas for health improvement and perceived future health needs [19]. Both questionnaires focus on health status in the previous four weeks prior to their administration.

Roosendaal et al. [20] were among the first to evaluate QoL in their cohort of patients with haemophilia. A self-administered questionnaire was sent to all their Dutch patients with haemophilia requesting information on employment, education, and joint impairment and a response rate of $81 \%$ (947 forms) was achieved. Results were compared to normal population data. The patient group was less 
likely to be married or have children and $41 \%$ had joint damage. Quality of life was assessed as a subjective measure as good or excellent in $80 \%$ which was no different to the population as a whole [20]. A study by Albrecht and Devlieger [17] also reported that in interviews with 153 people who had developed a range of disabilities over $50 \%$ reported a good or excellent QoL. This situation when people with apparent less optimal health report that they have good QoL has been labelled 'the disability paradox'. This appeared to relate to the subjects being in control of their life, being able to support others and having religious faith which provided a purpose in life. Other interviewees reported that a re-evaluation of priorities after the onset of their ill health and the ability to cope well with their disability which gave a sense of achievement were also important factors in how they viewed their QoL [17]. It was interesting to note that these changes in perception often occurred some time after the onset of the illness rather than immediately.

Although Roosendaal et al. [20] reported that patients with haemophilia had a QoL equal to the general population, other studies investigating QoL have identified that patients with haemophilia were more likely to have poorer QoL [11] [21], [22]. Miners et al. [11] evaluated QoL using the SF 36 in 168 patients with varying degrees of severity of haemophilia and identified that severely affected patients were more likely to have poorer QoL. Aznar et al. [21] evaluated the orthopaedic status of 70 severely affected patients with haemophilia with a median age of 22 years and administered the SF 36. Significant differences were identified for all dimensions of the SF 36 except role-emotional and mental health suggesting that QoL was poorer for the haemophilic group than for a similarly age matched group of normal males. Mohlo et al. [22] also used the SF 36 in a large multi-centre haemophilia study in France and identified that the domains, 'pain', 'general health' and 'vitality' scored poorly suggesting that those aspects of QoL were most affected.

Several factors have been perceived to reduce QoL in patients with haemophilia. These include being HIV positive, having impairments due to arthropathy or repeated bleeds and also a history of orthopaedic surgery.

Djulbegovic et al. [23] used two outcome measures to evaluate QoL, the SF 36 and the quality of well being scale (QWB) to determine the impact of being HIV positive on QoL in a group of eight haemophilic patients who were HIV positive and eleven who were HIV negative. The SF 36 demonstrated lower scores for 'health 
perception' and 'pain domains' suggesting poorer QoL in patients who were HIV positive. The QWB scale assesses mobility, physical activity and social activity to provide an overall score of health status [24] and resulted in a lower score for the HIV positive patients [23]. Tanaka et al. [25] used the AIMS2 and a satisfaction with daily life (SDL) questionnaire to evaluate QoL in 21 asymptomatic HIV positive and 17 HIV negative patients. The AIMS2 demonstrated that the HIV positive patients were significantly more dissatisfied with social activities and had lower mood. The SDL questionnaire identified more differences than the AIMS2 and was therefore considered to be more responsive. There were no significant differences between the groups in overall satisfaction or health perception [25]. There were also no differences in clinical severity of arthropathy between groups, however this was only determined by X-ray changes that may not be a sensitive measure of clinical symptoms [26]. The authors suggested that the differences were therefore due to the effects of being HIV positive [25].

Other studies have not identified a correlation between being HIV positive and lower QoL scores [11], [22]. These conflicting results may suggest that the method of evaluation may not be sensitive enough to detect differences or that being HIV positive does not necessarily further reduce QoL. It has been suggested that people with disabilities are able to maintain or re-establish a balance and adapt to a new health problem [17]. Other issues which may confound the evaluation of QoL are the occurrence of what has been termed 'beta change' or 'gamma change' [16] Beta change can occur if there is a change of perceptions due to previous experiences. Gamma change relates to a change in a patient's priorities following an illness or life event so that different degrees of importance are attached to the various domains [16]. Other mechanisms such as coping strategies, expectations and optimism can also influence QoL results [16] Some of these mechanisms were highlighted in the study by Albrecht and Devlieger [17] and need to be considered when evaluating outcome in patients with haemophilia.

The relationship between joint impairment and QoL has also been investigated [21], [22], [27]. The cross sectional study by Aznar et al. [21] included administration of the SF 36 and a clinical evaluation of knees, ankles and elbow joints based on the World Federation of Haemophilia (WFH) joint scoring system [28]. Joint measurements suggesting impairments were found to have a positive correlation with 'role physical' and 'vitality' dimensions of the SF 36. Mohlo et al. [22] identified that younger patients appeared to have a better QoL and this was 
hypothesised to be due to reduced joint dysfunction that was associated with more effective factor replacement regimens [22]. Solovieva [27] also used the SF 36 and a questionnaire to determine the clinical manifestations of arthropathy in 150 patients with haemophilia. An increase in morbidity correlated with the domains, 'physical role', 'bodily pain', 'vitality' and 'social functioning' in the SF 36 suggesting that those patients with more disability had poor scores in those domains. Overall, these results suggest that greater joint impairments are associated with poorer QoL.

Other factors considered to influence QoL are bleeding frequency or history of orthopaedic surgery. Miners et al. [11] identified that these variables did not correlate with QoL scores and suggested that the SF 36 may not be sensitive enough for patients with haemophilia. However, Mohlo et al. [22] identified that those patients who required orthopaedic treatment or who had more joint bleeds had poorer QoL scores.

The SF 12, a shortened version of the SF 36 has been used as part of a battery of assessment tools to evaluate QoL in patients with haemophilia undergoing total knee replacements [29]. The results demonstrated improvements in scores post operatively but the results were still lower than normal values suggesting that other joint impairments were influencing the scores. Unfortunately both pre and postoperative evaluations were only performed after the surgery and this may have influenced how the patients perceived their pre operative health [29].

Only one study has reported on the use of a QoL outcome measure to evaluate physiotherapy [30]. The original AIMS questionnaire was used to evaluate the effectiveness of an individualised physiotherapy programme for an unspecified number of patients with haemophilia. Few details were provided but the results indicated an improvement in impairment measures and significant improvements in AIMS scores following physiotherapy. The results helped to ensure that the physiotherapy service became permanent and was funded by the purchasers [30].

Overall the results of the published studies demonstrated a lower QoL in patients with haemophilia compared to normal population figures (see Table 1). The effect of being HIV positive as well as having haemophilia demonstrated conflicting results on QoL. The two studies that used the SF 36 demonstrated that being HIV positive had no apparent effect on QoL whereas other measures identified even 
lower QoL scores in this group. This may suggest that the SF 36 is not sensitive enough to detect any changes in health status. It has been reported in a review of QoL measures suitable for HIV positive patients that the SF 36 does not assess 'cognitive distress' and that other assessment tools are required to assess this domain [24].

Joint impairments were correlated with reduced QoL. This is not unexpected in view of the marked physical health problems that these patients still experience. Albrecht and Devlieger [17] identified that factors associated with poor ratings of health included the occurrence of pain and fatigue, components that are very pertinent for patients with haemophilic arthropathy. Overall, the results would suggest that more effective prophylactic regimens which aim to reduce impairments do improve QoL. However, the variability of factor replacement regimens within the patient cohorts and the cross sectional nature of the reported studies make it difficult to exclude other variables.

The SF 36 has not been specifically validated in patients with haemophilia but its value has been demonstrated in patients with arthritic conditions [21]. However patients with haemophilia have a different pattern of arthritis that may not be comparable to other arthritic conditions. The SF 36 has also been reported to demonstrate 'floor' effects in patients on renal dialysis [31] suggesting that it may not be responsive enough to detect changes in health status in some conditions [12]. 'Ceiling effects' have also been reported, particularly in functional domains [32] although again these effects have not been specifically investigated in patients with haemophilia and therefore require further investigation.

The validity and reliability of the Dutch version of the AIMS2 have been reported as satisfactory in a haemophilic group [33]. The domains 'social interaction' and 'symptoms' scored highest in their study suggesting more marked problems in those areas. Sections of the AIMS2 on hand and finger function are less relevant in patients with haemophilia as hand bleeds are rarely reported [1]. Van Meeteren et al. [33] suggested that this item should be redesigned. It has also been suggested that the use of a generic outcome measure, such as the SF 36 and a disease specific measure, such as the AIMS2 may be more valuable than using one tool in isolation to assess QoL [18]. 


\section{Evaluation of Physical Status}

The musculoskeletal system of a patient with haemophilia needs to be monitored on a long term basis as there may be a gradual loss of range of movement over time in the knees, ankles and elbows and other joints in the presence of arthropathy [34]. Ideally an annual review is undertaken to evaluate the musculoskeletal system and to determine any deterioration in joint range or muscle strength so that appropriate intervention such as physiotherapy can be undertaken if necessary. A standardised assessment form may assist in the collection of data [8]. The classification developed by the Orthopaedic Advisory Committee of the World Federation of Haemophilia can also be used to assess musculoskeletal function [28]. However it was designed at a time when factor replacement was less available and consequently more severe arthropathy tended to result. It may not be sensitive enough to detect the more minor changes which may be apparent in children and young adults at the present time [35]. Preliminary investigation has suggested that a revised version of the WFH scale, the Colorado Physical examination instrument and a newly developed Child Physical Examination instrument may be more appropriate in evaluating musculoskeletal function in younger patients with haemophilia [35].

\section{Evaluation of Orthopaedic Surgery}

Orthopaedic surgery may be performed for patients with haemophilia to manage severe arthropathy when conservative methods have failed. The use of total joint replacements can be beneficial in relieving the symptoms of chronic arthropathy but it is also important to identify and use robust measures to evaluate the procedures. The Hospital for Special Surgery (HSS) knee rating scale has been most commonly used to evaluate changes following total knee replacement in patients with haemophilia. This scale includes assessment of pain, function, range of movement, strength and stability [36]. Each parameter is weighted to give a maximum score out of 100 , where $85-100$ is rated as excellent, 70-84 is good, 6069 is fair and under 60 is classified as unsatisfactory [37]. Studies using the HSS scale generally report good or excellent scores post surgery in patients with haemophilia (for a review of studies see Beeton et al [38]). However it is recognised that patients who have many joints affected may not demonstrate such good improvements in scores post operatively as patients with an isolated knee problem [37]. This may be an issue for patients with haemophilia. Pain is almost always improved following surgery however the overall range of movement may not change although the flexion deformity may improve [38]. Therefore these patients 
may score less well on the rating scale even though they may have improved function and be painfree. For this reason other methods of evaluating outcome may also need to be considered.

Total hip replacements are less commonly undertaken for patients with haemophilia and standardised measures of evaluation not so widely used. In a recent review of total hip replacements in haemophilic patients only one study had used a standardised rating scale [38]. Increased use of standardised measures may be valuable in providing more robust evaluation of the benefits of surgery of this kind.

\section{Conclusion}

Further investigation into the methods of evaluation of outcome of care in patients with haemophilia needs to be undertaken. Currently standardised QoL measures, impairment measures and rating scales for surgical procedures are used. Further studies would be useful to explore these tools and other instruments in more depth in order to identify the most appropriate methods of evaluating the outcome of various interventions. Ultimately specific measures which are valid, reliable and responsive to changes in the health status of patients with haemophilia may need to be developed. 
Table 1

Summary of Results of Quality of Life Studies

\begin{tabular}{|c|c|c|c|}
\hline $\begin{array}{l}\text { Quality of life } \\
\text { evaluation }\end{array}$ & Results & $\begin{array}{l}\text { Measurement } \\
\text { tool }\end{array}$ & Author \\
\hline \multirow[t]{4}{*}{ Overall QoL rating } & $\begin{array}{l}\text { Equal to normal } \\
\text { population }\end{array}$ & Subjective rating & $\begin{array}{l}\text { Roosendaal et al } \\
1990\end{array}$ \\
\hline & $\begin{array}{l}\text { Lower than normal } \\
\text { population }\end{array}$ & SF 36 & Miners et al 1999 \\
\hline & $\begin{array}{l}\text { Lower than normal } \\
\text { population }\end{array}$ & SF 36 & Aznar er al 2000 \\
\hline & $\begin{array}{l}\text { Lower than normal } \\
\text { population }\end{array}$ & SF 36 & Mohlo et al 2000 \\
\hline \multirow{6}{*}{$\begin{array}{l}\text { Effect of being HIV } \\
\text { positive on QoL }\end{array}$} & No difference & SF 36 & Miners et al 1999 \\
\hline & No difference & SF 36 & Mohlo et al 2000 \\
\hline & $\begin{array}{l}\text { Lower QoL scores } \\
\text { in 'health } \\
\text { perception' and } \\
\text { 'pain' }\end{array}$ & SF 36 & $\begin{array}{l}\text { Djulbegovic et al } \\
1996\end{array}$ \\
\hline & Lower QoL score & QWB & $\begin{array}{l}\text { Djulbegovic et al } \\
1996\end{array}$ \\
\hline & $\begin{array}{l}\text { Lower QoL scores } \\
\text { in 'social activities' } \\
\text { and 'mood' }\end{array}$ & AIMS & Tanaka et al 1999 \\
\hline & Lower QoL scores & SDL & Tanaka et al 1999 \\
\hline \multirow[t]{2}{*}{$\begin{array}{l}\text { Effect of joint } \\
\text { impairment on } \\
\text { QoL }\end{array}$} & $\begin{array}{l}\text { Correlated with } \\
\text { 'role physical' and } \\
\text { 'vitality' }\end{array}$ & SF 36 & Aznar et al 2000 \\
\hline & $\begin{array}{l}\text { Correlated with } \\
\text { 'role physical' } \\
\text { 'bodily pain', } \\
\text { 'vitality' and 'social } \\
\text { functioning' }\end{array}$ & SF 36 & Solovieva 2001 \\
\hline \multirow{2}{*}{$\begin{array}{l}\text { Effect of bleeding } \\
\text { frequency on QOL }\end{array}$} & No correlation & SF 36 & Miners et al 1999 \\
\hline & $\begin{array}{l}\text { Positive correlation } \\
\text { with 'physical } \\
\text { function', 'pain', } \\
\text { 'restrictions due to } \\
\text { physical problems' } \\
\text { and 'emotional } \\
\text { problems' }\end{array}$ & SF36 & Mohlo et al 2000 \\
\hline $\begin{array}{l}\text { Effect of total knee } \\
\text { replacement on } \\
\text { QoL }\end{array}$ & $\begin{array}{l}\text { Improved scores, } \\
\text { still lower than } \\
\text { normal population }\end{array}$ & SF 12 & Schick et al 1999 \\
\hline $\begin{array}{l}\text { Effect of } \\
\text { physiotherapy on } \\
\text { QoL }\end{array}$ & Improved scores & AIMS & Cornwall 2000 \\
\hline
\end{tabular}

QWB = quality of well being scale

$\mathrm{SDL}=$ satisfaction with daily life 


\section{References}

1 Rodriguez-Merchan EC. Effects of haemophilia on articulations of children and adults. Clinical Orthopaedics and Related Research 1996; 328: 7-13.

2 Nilsson I, Berntorp E, Lofqvist $T$ et al. Twenty-five years experience of prophylactic treatment in severe haemophilia A and B. Journal of Internal Medicine 1992; 232: 25-32.

3 Liesner R, Khair K, Hann I. The impact of prophylactic treatment on children with severe haemophilia. British Journal of Haematology 1996; 92: 973-8.

4 Lowe G. Relationship between factor VIII replacement therapy and joint damage in severe haemophilia. Blood Coagulation and Fibrinolysis 1997; 8: 53-5.

5 Miners A, Sabin C, Tolley K et al. The changing patterns of factor VIII (FVIII) and factor IX (FIX) clotting factor usage in a comprehensive care centre between 1980 and 1994. Haemophilia 1998; 4: 4-9.

6 Lee C, Sabin C, Miners A. High cost, low volume care: the case of haemophilia. British Medical Journal 1997; 315: 962-3.

7 Department of Health UK. A First Class Service. Quality in the New NHS. London: HMSO, 1998.

8 Haemophilia Chartered Physiotherapists Association. Standards for Haemophilia. London: Chartered Society of Physiotherapy, 1996.

9 Chartered Society of Physiotherapy. Core standards of physiotherapy practice. London: Chartered Society of Physiotherapy, 2000.

10 Szucs T, Offner A, Schramm W. Socioeconomic impact of haemophilia care: results of a pilot study. Haemophilia 1996; 2: 211-7.

11 Miners A, Sabin C, Tolley $\mathrm{K}$ et al. Assessing health-related quality-of-life in individuals with haemophilia. Haemophilia 1999; 5: 378-85.

12 Bowling A. Measuring Health. A Review of Quality of Life Measurement Scales, 2nd edn. Buckingham: Open University Press, 1997.

13 Brazier J, Harper R, Jones $\mathrm{N}$ et al. Validating the SF-36 health survey questionnaire: new outcome measure for primary care. British Medical Journal 1992; 305: 160-4.

14 McDowell I, Newell C. Measuring health. A Guide to Rating Scales and Questionnaire, 2nd edition. Oxford: Oxford University Press, 1996.

15 Fuhrer M. Subjective well being: implications for medical rehabilitation outcomes and models of disablement. American Journal of Physical Medicine and Rehabilitation 1994; 73: 358-64.

16 Allison P, Locker D, Feine J. Quality of life: a dynamic construct. Social Science and Medicine 1997; 45: 221-30.

17 Albrecht $G$, Devlieger $P$. The disability paradox: high quality of life against all odds. Social Science and Medicine 1999; 48: 977-88.

18 Ware JE. Measuring patients' views: the optimum outcome measure. British Medical Journal 1993; 306: 1429-30.

19 Meenan R, Mason J, Anderson J et al. AIMS2 The content and properties of a revised and expanded arthritis impact measurement scales health status questionnaire. Arthritis and Rheumatism 1992; 35: 1-10.

20 Roosendaal F, Smit C, Varekamp I et al. Modern haemophilia treatment: medical improvements and quality of life. Journal of Internal Medicine 1990; 228: $633-40$.

21 Aznar J, Magallon M, Querol F et al. The orthopaedic status of severe haemophiliacs in Spain. Haemophilia 2000; 6: 170-6.

22 Mohlo $\mathrm{P}$, Rolland $\mathrm{N}$, Lebrun $\mathrm{T}$ et al. Epidemiological survey of the orthopaedic status of severe haemophilia A and B patients in France. Haemophilia 2000; 6: 23-32. 
23 Djulbegovic B, Goldsmith G, Vaughn D et al. Comparison of the quality of life between HIV-positive haemophilia patients and HIV-negative haemophilia patients. Haemophilia 1996; 2: 166-72.

24 Hays R, Shapiro M. An overview of generic health-related quality of life measures for HIV research. Quality of Life Research 1992; 1: 91-7.

25 Tanaka S, Hachisika K, Okazaki T et al. Health status and satisfaction of asymptomatic HIV-positive haemophiliacs in Kyushu, Japan. Haemophilia 1999; 5: 56-62.

26 Grieve G. Common Vertebral Joint Problems, 2nd edition. Edinburgh: Churchill Livingstone, 1988.

27 Solovieva S. Clinical severity of disease, functional disability and healthrelated quality of life. Three year follow-up study of 150 Finnish patients with coagulation disorders. Haemophilia 2001; 7: 53-63.

28 Pettersson H, Gilbert M. Diagnostic Imaging in Haemophilia. Berlin: Springer-Verlag, 1985.

29 Schick M, Stucki G, Rodriguez M et al. Haemophilic Arthropathy: Assessment of quality of life after total knee arthroplasty. Clinical Rheumatology 1999; 18: 468-72.

30 Cornwall J. Disability and outcome measures in patients with haemophilia. In: Physiotherapy management of haemophilia (Buzzard B, Beeton K, eds). Oxford: Blackwell Science, 2000: 101-9.

31 Kurtin P, Ross Davies A, Meyer $\mathrm{K}$ et al. Patient-bases health status measures in outpatient dialysis. Medical Care 1992; 30: MS136-MS49.

32 Anderson R, Aaronson N, Wilkin D. Critical review of the international assessments of health-related quality of life. Quality of Life Research 1993; 2: 369-95.

33 Van Meeteren N, Strato I, Van Veldhoven $\mathrm{N}$ et al. The utility of the Dutch Arthritis impact measurement scales 2 for assessing health status in individuals with haemophilia: a pilot study. Haemophilia 2000; 6: 664-71.

34 Johnson $R$, Babbitt $D$. Five stages of joint disintegration compared with range of motion in hemophilia. Clinical Orthopaedics and Related Research 1985: 36-42.

35 Manco-Johnson M, Nuss R, Funk $S$ et al. Joint evaluation instruments for children and adults with haemophilia. Haemophilia 2000; 6: 649-57.

36 Insall J, Ranawat C, Aglietti $\mathrm{P}$ et al. A comparison of four models of total knee-replacement prostheses. Journal Bone and Joint Surgery 1976; 58-A: 754-65.

37 Insall J, Scott W, Ranawat C. The total condylar knee prosthesis. A report of two hundred and twenty cases. Journal Bone and Joint Surgery (Am) 1979; 61-A: 173-80.

38 Beeton K, Rodriguez-Merchan E, Alltree J. Total joint arthroplasty in haemophilia. Haemophilia 2000; 6: 474-81. 